\title{
Heterogeneous Oxidation of Methylene Blue with Surface-Modified Iron-Amended Activated Carbon
}

\author{
Jihyun R. Kim, Branden Santiano, Hyosang Kim, Eunsung Kan* \\ Department of Molecular Bioscience and Bioengineering, University of Hawaii at Manoa, Honolulu, USA \\ Email: *ekan@hawaii.edu
}

Received May 18, 2013; revised June 19, 2013; accepted July 7, 2013

Copyright (C) 2013 Jihyun R. Kim et al. This is an open access article distributed under the Creative Commons Attribution License, which permits unrestricted use, distribution, and reproduction in any medium, provided the original work is properly cited.

\begin{abstract}
The present study aims to develop effective adsorption and oxidation of synthetic dye in wastewater by using the newly synthesized iron-amended activated carbon. Recently synthetic dye-containing wastewater has gained more attention due to its mass discharge, high toxicity and low biodegradation. For enhancing adsorption of dye and oxidative regeneration of dye-exhausted activated carbon, the novel amendment of iron-deposited granular activated carbon (GAC) was developed. It was to amend ferrous ion onto the acid-pretreated $\mathrm{GAC}$ when $\mathrm{pH}$ of iron solution was higher than the $\mathrm{pH}$ at point of zero charge $(\mathrm{pH}, \mathrm{pzc})$ of the GAC. Methylene blue (MB) in water was adsorbed onto the acid-treated ironamended GAC (Fe-GAC) followed by single or multiple applications of $\mathrm{H}_{2} \mathrm{O}_{2}$. Batch experiments were carried out to study the adsorption isotherm and kinetics indicating adsorption of MB onto the Fe-GAC followed Langmuir isotherm and the pseudo-second order kinetics. The Fe-GACshowed the maximum adsorption capacity $\left(q_{\mathrm{m}}\right)$ of $238.1 \pm 0.78 \mathrm{mg} / \mathrm{g}$ which was higher than the virgin GAC with $q_{\mathrm{m}}$ of $175.4 \pm 13.6 \mathrm{mg} / \mathrm{g}$ at $20^{\circ} \mathrm{C}, \mathrm{pH} 6$ and the initial concentration of 20 $200 \mathrm{mg} / \mathrm{L}$. The heterogeneous Fenton oxidation of MB in the Fe-GAC revealedthat increasing the $\mathrm{H}_{2} \mathrm{O}_{2}$ loading from 7 to $140 \mathrm{mmol} \mathrm{H}_{2} \mathrm{O}_{2} / \mathrm{mmol} \mathrm{MB}$ led to enhancing the oxidation efficiency of MB in the GAC from $62.6 \%$ to $100 \%$ due to the increased generation of hydroxyl radicals. Further enhancement of oxidation of MB in the Fe-GAC was made by the multiple application of $\mathrm{H}_{2} \mathrm{O}_{2}$ while minimizing $\mathrm{OH}$ radical scavenging often occurring at high concentration of $\mathrm{H}_{2} \mathrm{O}_{2}$. Therefore, the acid-treated iron-amended GAC would provide excellent adsorption capacity for MB and high oxidation efficiency of $\mathrm{MB}$ in the $\mathrm{GAC}$ with multiple applications of $\mathrm{H}_{2} \mathrm{O}_{2}$ and optimum iron loading.
\end{abstract}

Keywords: Adsorption; Activated Carbon; Iron-Amended Activated Carbon; Heterogeneous Oxidation; Fenton Oxidation; Methylene Blue

\section{Introduction}

Synthetic dyes are widely used for textile, pulp and paper, plastic, food, cosmetic and pharmaceutical industries [1]. With mass production of synthetic dyes and mass discharge of synthetic dye-containing wastewater, effective treatment of dye-containing wastewater has gained more attention for the past decades [2]. Degradation of synthetic dyes is difficult because of their complex aromatic structure and nature of the lead compounds. Besides, the intermediate and byproducts of most of dye chemicals are considered to be harmful to aquatic organisms due to their toxicity and carcinogenic activity [3]. Therefore, efficient and cost-effective treatment processes of dyecontaining wastewater need to be developed [4].

Adsorption using granular activated carbon (GAC) as one of most reliable methods has been used to remove

"Corresponding author. dyes in wastewater. It is simple, effective and independent from toxicity of dye chemicals. However, regeneration of dye-exhausted activated carbon determines the overall operating costs because the dye-spent activated carbon needs to be regenerated to achieve its re-adsorptive capacity. For most of cases involving GAC regeneration, the spent GAC is thermally regenerated either on-site or transported to a thermal regeneration facility and regenerated off-site. The current thermal regeneration method often leads to significant deterioration of the carbon pore structure, specific surface area and functionality which influences on re-adsorptive capacity of contaminant-spent activated carbon [5].

Alternative to the thermal regeneration, Fenton oxidation-driven regeneration of the spent GAC is a treatment option under development to regenerate the GAC on-site and in situ. It has shown excellent performance to oxidize various contaminants including MTBE, BTEX, TCE 
and chlorobenzene from the activated carbon [6,7]. The Fenton oxidation-driven regeneration relies on heterogeneous Fenton oxidation which oxidizes contaminants at the GAC by using $\mathrm{OH}$ radicals generated by reaction between $\mathrm{H}_{2} \mathrm{O}_{2}$ and iron immobilized at the GAC [7]. Thus, it leads to effective oxidation of contaminants at surface of the GAC with little generation of iron sludge which is different from mass production of iron sludge by homogeneous Fenton oxidation. For heterogeneous Fenton oxidation, iron amendment onto the GAC is of prime importance to determine oxidation efficiency of contaminants in the GAC since more uniform iron amendment onto the GAC minimizes intraparticle diffusion limitation, the rate-limiting step during heterogeneous Fenton oxidation in the GAC [7].

For this study, the acid-treated iron-amended GAC (Fe-GAC) was synthesized by amending $\mathrm{Fe}^{2+}$ onto the acid-pretreated GAC at the conditions that the $\mathrm{pH}$ of $\mathrm{Fe}^{2+}$ solution was higher than the $\mathrm{pH}$ at point of zero charge $\left(\mathrm{pH},{ }_{\mathrm{pzc}}\right)$ of the GAC. As reported by Kan and Huling [8], the acid-treatment of the GAC was conducted to increase acidic surface groups containing oxygen and to lower $\mathrm{pH}$, pzc of the GAC. When the acid-treated GAC was suspended in the $\mathrm{Fe}^{2+}$ solution at the conditions that the $\mathrm{pH}$ of ferrous solution was higher than the $\mathrm{pH}$, pzc of the acid-treated GAC, the more negatively charged surface of the acid-treated GAC enhanced electrostatic attraction with $\mathrm{Fe}^{2+}$ for making more uniform $\mathrm{Fe}$ deposition into the GAC [7]. The more uniform Fe deposition into the GAC would help effective oxidation of the contaminants in the GAC with steady diffusion and reaction of $\mathrm{H}_{2} \mathrm{O}_{2}$ into the pores of the GAC.

Therefore, the present study characterized the adsorption capacity and the oxidation efficiency of the acidtreated Fe-amended GAC (Fe-GAC) for treating MBcontaminated water. The adsorption isotherm and kinetics using the Fe-GAC were analyzed for understanding the major mechanisms associated with adsorption of $\mathrm{MB}$ onto the Fe-GAC. The oxidation efficiency of MB in the Fe-GAC by heterogeneous Fenton oxidation was investigated at various iron and $\mathrm{H}_{2} \mathrm{O}_{2}$ loading.

\section{Materials and Methods}

\subsection{Adsorbent and Adsorbate}

The GAC (URV, $8 \times 30$ mesh, Calgon Carbon Corp., Pittsburgh, PA) was derived from bituminous coal and activated in a manner to minimize $\mathrm{H}_{2} \mathrm{O}_{2}$ reactivity (Harrision, CalgonCarbon personal communication). The GAC was rinsed with deionized (DI) water, dried in an oven at $105^{\circ} \mathrm{C}$, and stored in a desiccator until used. The surface area and pore volume of the GAC as received was $1290 \mathrm{~m}^{2} / \mathrm{g}$ and $0.64 \mathrm{~mL} / \mathrm{g}$, respectively [6]. Methylene blue (Figure 1, Fisher Scientific, Waltham MA), a cationic dye, which is difficult to be degraded in a natural environment, was chosen as the model adsorbate. A standard stock solution of $1000 \mathrm{mg} / \mathrm{L}$ was prepared and suitably diluted to the required initial concentration.

\subsection{Preparation of Fe-Amended Activated Carbon}

A stock solution of ferrous chloride was prepared immediately before the Fe solution was amended to the GAC by dissolving ferrous chloride $\left(\mathrm{FeCl}_{2} \cdot 4 \mathrm{H}_{2} \mathrm{O}\right)$ into the DI water $\left(50 \mathrm{mg} / \mathrm{L}\right.$ as $\left.\mathrm{Fe}^{2+}\right)$. The acid-treated GAC was prepared by treating the $10 \mathrm{~g}$ virgin GAC with nitric acid at $\mathrm{pH} 3$ for $4 \mathrm{~d}$ for increasing the acidic surface oxides and lowering its $\mathrm{pH}, \mathrm{pzc}(\mathrm{pH}$ at point of zero charge). $\mathrm{A} \mathrm{pH}$, pzc is the $\mathrm{pH}$ at which positive and negative surface charges are equal and GAC surface has a net charge of zero.

The acidic treatment of the GAC was to enhance the electrostatic interaction between the GAC and $\mathrm{Fe}^{2+}$ for nearly uniform iron deposition in the GAC. The 6.3 $187.5 \mathrm{~mL}$ of $50 \mathrm{mg} \cdot \mathrm{L}^{-1} \mathrm{Fe}^{2+}$ was added to the $0.5 \mathrm{~g}$ the acid-treated GACs for iron amendment onto the GAC. After the iron amendment onto the acid-treated GACs, the GACs were rinsed three times with DI water to eliminate the chloride residual in the GACs and dried in an oven at $80^{\circ} \mathrm{C}$ for $24 \mathrm{~h}$.

\subsection{Batch Adsorption Studies}

The batch experiments for adsorption isotherm were conducted by suspending $25 \mathrm{mg}$ of the Fe-GAC in a series of flasks containing $50 \mathrm{~mL}$ of methylene blue solutions at the concentration of $0.02-0.2 \mathrm{~g} / \mathrm{L}$. The initial $\mathrm{pH}$ of $\mathrm{MB}$ solution ( $\mathrm{pH}=6.0$ ) was adjusted by adding $0.1 \mathrm{M}$ $\mathrm{HNO}_{3}$ or $0.1 \mathrm{M} \mathrm{NaOH}$. The initial concentrations of $\mathrm{MB}$ were obtained by measuring O.D. at $663 \mathrm{~nm}\left(\lambda_{\max }\right)$ using BioSpec-mini UV-Vis spectrophotometer (Shimadzu, Carlsbad CA). The Fe-GAC used for the adsorption isotherm experiments contained $6 \mathrm{mg} \mathrm{Fe} / \mathrm{g}$ GAC. The adsorption process was carried out by agitating at the constant speed $(200 \mathrm{rpm})$ at room temperature $\left(20^{\circ} \mathrm{C}\right)$ for $72 \mathrm{~h}$ to ensure equilibrium was reached. The post-sorption $\mathrm{MB}$ solution was sampled after equilibrium ( $>3 \mathrm{~d}$ ) in replicate and analyzed. The Differences between initial and final concentrations were used to calculate the mass of MB adsorbed to the GAC. The MB uptake at equilibrium, $q_{\mathrm{e}}$ $(\mathrm{mg} / \mathrm{g})$, was calculated by Equation (1):

$$
q_{\mathrm{e}}=\frac{\left(C_{0}-C_{e}\right) V}{W}
$$

where $C_{0}$ and $C_{e}(\mathrm{mg} / \mathrm{L})$ are the liquid-phase concentration of dye at initial and at equilibrium, respectively. $V$ (L) is the volume of the solution, and $W(\mathrm{~g})$ is the mass of dry adsorbent used. All samples were centrifuged prior 
to analysis to minimize the interference of carbon fines with the analysis.

For understanding the adsorption mechanism and capacity of the GAC, the Langmuir and Freundlich isotherm models were used to interpret the batch isotherm data. The Langmuir equation [9] is valid for monolayer adsorption on a surface with a finite number of identical sites while Freundlich model [10] is an empirical equation based on adsorption on a heterogeneous surface. The linear form of Freundlich and Langmuir isotherms are shown in Equations (2) and (3), respectively:

Freundlich isotherm:

$$
\ln q_{e}=\ln k_{f}+(1 / n) \ln C_{e}
$$

Langmuir isotherm:

$$
C_{e} / q_{e}=1 / K_{L} q_{\max }+C_{e} / q_{\max }
$$

where $\ln k_{f}$ is roughly a measure of the maximum adsorption capacity and $1 / n$ is an indicator of adsorption effectiveness; $q_{\max }$ is the maximum adsorption capacity $(\mathrm{mg} / \mathrm{g})$ corresponding to complete monolayer coverage of the surface, $q_{e}$ is the amount of dye adsorbed per unit mass of adsorbent $(\mathrm{mg} / \mathrm{g}), C_{e}$ is the liquid-phase concentration of dye at equilibrium and $K_{L}$ is the Langmuir constant $(\mathrm{L} / \mathrm{g})$ related to the sorption/desorption energy.

\subsection{Effect of $\mathrm{pH}$}

The effect of $\mathrm{pH}$ on the color removal and adsorption capacity of $\mathrm{MB}$ was analyzed over the $\mathrm{pH}$ range from 3 to 11 . The $\mathrm{pH}$ was adjusted using $0.1 \mathrm{M} \mathrm{HCl}$ and $0.1 \mathrm{M}$ $\mathrm{NaOH}$ solutions. The dye solution $(60 \mathrm{~mL})$ at concentration of $1000 \mathrm{mg} / \mathrm{L}$ with $0.5 \mathrm{~g}$ of acid-treated Fe amended GAC was shaken for $72 \mathrm{~h}$ at room temperature $\left(20^{\circ} \mathrm{C}\right)$ on a shaker at a constant speed of $200 \mathrm{rpm}$. The samples were then centrifuged and analyzed using a UV spectrophotometer.

\subsection{Adsorption Kinetics}

Adsorption kinetic experiments were carried out by suspending $0.5 \mathrm{~g}$ of the Fe-GAC in $60 \mathrm{~mL}$ of each MB solution at initial concentrations of $80 \mathrm{mg} / \mathrm{L}$ to $1000 \mathrm{mg} / \mathrm{L}$, a $\mathrm{pH} 6$ and 20 for $24 \mathrm{~h}$ under mixing. Aliquots of $0.1 \mathrm{~mL}$ to $1 \mathrm{~mL}$ depending on the solution of concentration were withdrawn at different time intervals, centrifuged and analyzed for the MB concentration using a UV spectrophotometer. The kinetic of the adsorption were analyzed using two different kinetic models: the pseudo-first order and pseudo-second order. The pseudo-first order kinetic model is given by Lagergren [11]:

$$
\frac{\mathrm{d} q}{\mathrm{~d} t}=k_{1}\left(q_{e}-q\right)
$$

where $q$ and $q_{e}$ represent the amount of dye adsorbed $(\mathrm{mg} / \mathrm{g})$ at any time $t$ and at equilibrium time, respectively, and $k_{1}$ represents the sorption rate constant $\left(\mathrm{min}^{-1}\right)$. Integrating Equation (4) with respect to boundary conditions $q=0$ at $t=0$ and $q=q_{t}$ at $t=t$, then Equation (4) becomes:

$$
\ln \left(q_{e}-q_{t}\right)=\ln q_{e}-k_{1} t
$$

where $q_{e}$ and $q_{\mathrm{t}}(\mathrm{mg} / \mathrm{g})$ are the amounts of adsorbate adsorbed at equilibrium and at any time, $t(\mathrm{~min})$, respectively, and $k_{1}\left(\mathrm{~min}^{-1}\right)$ is the adsorption rate constant. Thus the rate constant $k_{1}\left(\mathrm{~min}^{-1}\right)$ and $q_{e}$ can be calculated from the plot of $\ln \left(q_{e}-q_{\mathrm{t}}\right)$ versus time $t$.

The pseudo-second-order equation [12] based on equilibrium adsorption is expressed as:

$$
\frac{\mathrm{d} q}{\mathrm{~d} t}=k_{2}\left(q_{e}-q\right)^{2}
$$

where $k_{2}(\mathrm{~g} / \mathrm{mg} \mathrm{min})$ is the rate constant of second-order adsorption, $q_{e}$ and $q$ represent the amount of dye adsorbed $(\mathrm{mg} / \mathrm{g})$ at equilibrium and at any time $t$. Separating the variables in Equation (6) gives:

$$
\frac{\mathrm{d} q}{\left(q_{e}-q\right)^{2}}=k_{2} \mathrm{~d} t
$$

Integrating Equation (7).with respect to boundary conditions $t=0$ to $t=t$ and $q=0$ and $q=q_{e}$ gives

$$
\frac{t}{q}=\frac{1}{k_{2} q_{e}^{2}}+\frac{1}{q_{e}} t
$$

The rate constant of second-order adsorption $\left(k_{2}\right)$ and $q_{e}$ will be evaluated from the linear plot $t / q_{t}$ versus $t$.

\section{6. pH, Point of Zero Charge}

The $\mathrm{pH}$ at point of zero charge $(\mathrm{pH}, \mathrm{pzc})$ of the GAC was determined using the $\mathrm{pH}$ drift method [7]. The $50 \mathrm{~mL}$ of DI water amended with $0.01 \mathrm{M} \mathrm{NaCl}$ was placed in the $100 \mathrm{~mL}$ amber vials and sparged with $\mathrm{N}_{2}(200 \mathrm{~mL} / \mathrm{min}$; $10-15 \mathrm{~min}$ ) to eliminate $\mathrm{CO}_{2}$ and to stabilize $\mathrm{pH}$. The $\mathrm{pH}$ was adjusted from $\mathrm{pH} 2$ to $\mathrm{pH} 11$ in a series of vials by adding either $\mathrm{HCl}$ or $\mathrm{NaOH}$ while purging the headspace with $\mathrm{N}_{2} .0 .15 \mathrm{~g}$ of the GAC was added and the vial was capped immediately. The final $\mathrm{pH}(\mathrm{pH}$, final ) was measured in each of the vials after $48 \mathrm{~h}$ and plotted versus the initial $\mathrm{pH}(\mathrm{pH}$, initial $)$. The $\mathrm{pH}$, pzc was determined graphically at the intersection of $\mathrm{pH}$, final and the line $\mathrm{pH}$, final $=\mathrm{pH}$, initial.

\subsection{Heterogeneous Fenton Oxidation of the MB-Saturated Fe-GAC}

The effect of various iron loading (0.5 to $15 \mathrm{mg} \mathrm{Fe} / \mathrm{g}$ GAC) on the oxidation efficiency of MB in the Fe-GAC was investigated. The oxidation of the MB-saturated $\mathrm{Fe}-\mathrm{GAC}$ was performed with a single injection of $3.0 \mathrm{~mL}$ 
of $30 \% \mathrm{H}_{2} \mathrm{O}_{2}\left(52.9 \mathrm{mmol} \mathrm{H}_{2} \mathrm{O}_{2} / \mathrm{g}\right.$ GAC; Sigma Aldrich, $\mathrm{MO})$ at $\mathrm{pH}$ of $3.0-3.5$. The $\mathrm{pH}$ of solution before adding $\mathrm{H}_{2} \mathrm{O}_{2}$ was between $3.0-3.5$. Since $\cdot \mathrm{OH}$ scavenging by high concentrations of $\mathrm{H}_{2} \mathrm{O}_{2}$ is a probable source of overall oxidation inefficiency [13], the multiple applications of $\mathrm{H}_{2} \mathrm{O}_{2}$ were made to minimize the initial $\mathrm{H}_{2} \mathrm{O}_{2}$ concentration and $\cdot \mathrm{OH}$ scavenging. $\mathrm{H}_{2} \mathrm{O}_{2}$ concentrations were monitored over time under complete mixing condition $\left(\mathrm{H}_{2} \mathrm{O}_{2}\right.$, initial of $\left.14.3 \mathrm{~g} / \mathrm{L}\right)$. The oxidation efficiency of $\mathrm{MB}$ in the GAC was evaluated by measuring the MB in the GAC after Fenton oxidation. Similarly, the effect of $\mathrm{H}_{2} \mathrm{O}_{2}$ concentration on oxidation of $\mathrm{MB}$ in the $\mathrm{Fe}-\mathrm{GAC}$ was investigated when various load of $\mathrm{H}_{2} \mathrm{O}_{2}$ (7 mmol to $140 \mathrm{mmol} \mathrm{H}_{2} \mathrm{O}_{2} / \mathrm{mmol} \mathrm{MB}$ ) at the fixed iron content in the $\mathrm{Fe}-\mathrm{GAC}$ ( $5 \mathrm{mg} \mathrm{Fe} / \mathrm{g} \mathrm{GAC}$ ) for determining the optimum load of $\mathrm{H}_{2} \mathrm{O}_{2}$.

The residual amount of MB in the Fe-GAC after Fenton oxidation was evaluated by extracting the $\mathrm{MB}$ in the Fe-GAC with $10-20 \mathrm{~mL}$ methanol for $3 \mathrm{~d}$. The MB desorption and diffusion rate from MB-spent GAC was evaluated using the fill and draw method. This involved post-sorption applications of the DI water $(60 \mathrm{~mL})$ to MB-spent GAC $(0.5 \mathrm{~g})$ and measuring MB in solution at a different time interval. The rates of desorption was calculated as the mass of MB desorbed from the GAC divided by the mass of GAC and time period of desorption. In all cases tested, most of MB in the GAC was not released to the aqueous phase and the concentration of $\mathrm{MB}$ in the aqueous phase wasfar below the equilibrium MB concentration.

\subsection{Effect of Semi-Continuous Feeding of $\mathrm{H}_{2} \mathrm{O}_{2}$ on Oxidation of MB in the Fe-GAC}

In order to investigate the effect of the semi-continuous feeding of $\mathrm{H}_{2} \mathrm{O}_{2}$ on increasing $\mathrm{MB}$ oxidation efficiency in the $\mathrm{Fe}-\mathrm{GAC}$, one fourth of $\mathrm{H}_{2} \mathrm{O}_{2}$ amount was added at four different points of time at every $12 \mathrm{~h}$. The initial $\mathrm{H}_{2} \mathrm{O}_{2}$ concentration $\left(28 \mathrm{mmol} \mathrm{H}_{2} \mathrm{O}_{2} / \mathrm{mmol} \mathrm{MB}\right.$ ) was selected from the previous experiment with the same iron load which was $6 \mathrm{mg} \mathrm{Fe} / \mathrm{g}$ GAC. The single point $\mathrm{H}_{2} \mathrm{O}_{2}$ injection from the previous section and semi-continuous feeding of $\mathrm{H}_{2} \mathrm{O}_{2}$ was evaluated the effectiveness of the $\mathrm{H}_{2} \mathrm{O}_{2}$ injections for oxidation ofthe MB in the Fe-GAC.

\subsection{Analytical Methods}

MB concentration in the supernatant solution after and before adsorption was determined using UV-Vis spectrophotometer at $663 \mathrm{~nm}$. The filtered samples using 0.2 $\mu \mathrm{m}$ membrane filters were measured for $\mathrm{H}_{2} \mathrm{O}_{2}(n=3)$ using amodified peroxytitanicacid colorimetric procedure with a detection limit of $0.1 \mathrm{mg} / \mathrm{L}$ [7]. Iron was measured in the GAC slurry solution using thePhenanthroline Method [7].

\section{Results and Discussion}

\subsection{Adsorption of MB onto the GACs}

\subsubsection{Adsorption Isotherm Analysis}

In order to estimate the adsorption capacity of GACs for $\mathrm{MB}$ and to optimize the design of adsorption system, it is important to analyze the adsorption equilibrium data. In the present study, the Freundlich and Langmuir isotherms that are the most commonly used isotherms were applied to investigate the overall adsorption efficacy and to characterize the $\mathrm{MB}$ adsorption process in the system using Fe-GAC. The isotherm parameters of the Freundlich and Langmuir models for the adsorption of MB on virgin GAC and the Fe-GAC obtained at temperature of $20^{\circ} \mathrm{C}$ after $72 \mathrm{~h}$, are summarized in Table 1. The results indicated that the maximum adsorption capacity of the Fe-GAC $\left(q_{\mathrm{m}}=238.1 \mathrm{~m} \pm 0.78 \mathrm{mg} / \mathrm{g}\right)$ in this study was higher compared with the virgin GAC $\left(q_{\mathrm{m}}=175.4 \pm 13.6\right.$ $\mathrm{mg} / \mathrm{g}$ ). The result indicates the maximum adsorption capacity of the activated carbon prepared in this study was comparable with the works done by other studies on adsorption of MB in GAC $\left(q_{\mathrm{m}}=240-299 \mathrm{mg} / \mathrm{g}\right)[14,15]$. Also, the analysis of the batch isotherm data supported that Langmuir isotherm model is the appropriate model for adsorption of MB onto the GAC indicating homogeneous monolayer adsorption of $\mathrm{MB}$ onto the site of the GAC.

\subsubsection{Effect of Initial MB Solution $\mathrm{pH}$ on Adsorption of Methylene Blue on Fe-GAC}

The $\mathrm{pH}$ of solution at which adsorption occurs is found to influence the extent of adsorption. The $\mathrm{pH}$ of MB solution affects adsorption in that it governs the degree of ionization of the acidic and basic functional groups in methylene blue (see Figure 1 for chemical structure of MB) [16]. The effect of initial $\mathrm{pH}$ of the MB solution on the amount of $\mathrm{MB}$ adsorbed was studied by varying the initial $\mathrm{pH}$ with constant process parameters. The experimental results indicated that the $\mathrm{pH}$ of initial MB solution did not possess any significant influence on the adsorption of methylene blue. The adsorption of MB at the

Table 1. Langmuir and Freundlich isotherm model coefficient for adsorption of MB on GACs. Conditions: Initial concentration of $\mathrm{MB}, 20$ - $120 \mathrm{mg} / \mathrm{L}$; volume of solution, 60 $\mathrm{mL}$; initial solution $\mathrm{pH}, 6.0$; temperature, $20^{\circ} \mathrm{C}$; contact time,72 h.

\begin{tabular}{ccccccc}
\hline & \multicolumn{3}{c}{ Freundlich } & \multicolumn{3}{c}{ Langmuir } \\
\hline MB & $q_{\max }$ & $n$ & $\mathrm{R}^{2}$ & $q_{\max }$ & $K_{L}$ & $\mathrm{R}^{2}$ \\
Virgin & 121.0 & 5.62 & 0.7841 & $175.4( \pm 13.6)$ & 3.36 & 0.9980 \\
GAC & 133.9 & 4.19 & 0.8920 & $238.1( \pm 0.78)$ & 2.96 & 0.9996 \\
Fe-GAC & 130. \\
\hline
\end{tabular}

$q_{\max }=$ the maximum adsorption capacity $(\mathrm{mg} / \mathrm{g}) ; n=$ an indicator of adsorption effectiveness; $K_{L}=$ the Langmuir constant $(\mathrm{L} / \mathrm{g})$. 
initial $\mathrm{pH}$ of 3 to 11 showed nearly complete uptake of methylene blue with the adsorption capacity of 123.9 to $135.1 \mathrm{mg} \mathrm{MB} / \mathrm{g}$ GAC(data not shown). This finding is different from others' investigation that initial $\mathrm{pH}$ value may enhance or depress adsorption of dye on activated carbon [17]. As reported by others, MB adsorption capacities are significantly improved at a higher solution $\mathrm{pH}[17,18]$. This can be explained by the electrostatic attraction (Table 2) between the positively charged MB (solution $\mathrm{pH}>\mathrm{pKa}, \mathrm{MB}$ ) and the negatively charged surface of activated carbon (solution $\mathrm{pH}>\mathrm{pH}$, pzc, Table 3). Increasing solution $\mathrm{pH}$ increases the number of hydroxyl groups thus, increases the number of negatively charged sites and enhances the attraction between dye and adsorbent surface [19]. However, the nearly constant adsorption capacity of Fe-GAC for $\mathrm{MB}$ over the $\mathrm{pH}$ range 3 to 11 in our study was an indication that the adsorption of $\mathrm{MB}$ on the Fe-GAC depends on both the electrostatic interaction and non-electrostatic such as van der Waals forces, hydrophobic interaction and hydrogen bonding in this system. It can be explained by the fact that adsorption of dye from aqueous solution on carbon is a complex interplay between non-electrostatic and electrostatic interactions [20].

\subsubsection{Adsorption Kinetics}

In order to investigate the mechanisms of MB adsorption on the Fe-GAC, the pseudo-first order and pseudo-second order kinetics models were used to fit the experimental data. The kinetic parameters of the pseudo-first<smiles>CN(C)c1ccc2nc3ccc(=[N+](C)C)cc-3sc2c1</smiles>

Figure 1. The molecular structure of methylene blue.

Table 2. Surface charge of the Fe-GAC and MB at various pH.

\begin{tabular}{|c|c|c|c|}
\hline $\mathrm{pH}$ & $\begin{array}{c}\text { Fe-GAC } \\
\left(\mathrm{pH},{ }_{\mathrm{pzc}}=5.0\right)\end{array}$ & $\begin{array}{c}\mathrm{MB} \\
(\mathrm{pKa}=3.8)\end{array}$ & Interactions \\
\hline$<3.8$ & $\begin{array}{l}\text { Positive charge } \\
\text { dominated }\end{array}$ & Non-charge & $\begin{array}{l}\text { Van der Waals } \\
\text { or hydrophobic }\end{array}$ \\
\hline $3.8<\mathrm{pH}<5.0$ & $\begin{array}{l}\text { Positive charge } \\
\text { dominated }\end{array}$ & $\begin{array}{l}\text { Positive } \\
\text { charge }\end{array}$ & $\begin{array}{l}\text { Van der Waals } \\
\text { or hydrophobic }\end{array}$ \\
\hline $\mathrm{pH}>5$ & $\begin{array}{l}\text { Negative charge } \\
\text { dominated }\end{array}$ & $\begin{array}{l}\text { Positive } \\
\text { charge }\end{array}$ & Electrostatic \\
\hline
\end{tabular}

Table 3. pH, pzc of the virgin, acid-treated and acid-treated iron amended GAC.

\begin{tabular}{cc}
\hline & $\mathrm{pH}, \mathrm{pzc}$ \\
\hline Virgin GAC & 5.4 \\
Acid-treated GAC & 4.2 \\
Fe-GAC & 5.0 \\
\hline
\end{tabular}

order and the pseudo-second order models were calculated from the linearized Equations (5) and (6), respectively. MB adsorption of the pseudo-second order kinetic fitting results is shown in Figure 2. The kinetic parameters acquired from fitting the results are summarized in Table 4. The correlation coefficient values for the pseudo-first order and pseudo-second order kinetic models were found to be close to one; however, the experimental $q_{e}$ values for the first-order kinetic model do not agree with the calculated ones whereas the pseudo-second ordershow a good agreement between experimental and calculated $q_{e}$ values.

The applicability of the kinetic model to describe the adsorption process was further validated by the normalized standard deviation, $\Delta q_{e}(\%)$, which is defined as:

$$
\Delta q_{e}=100 \times \sqrt{\frac{\sum\left[\frac{q_{e, \text { exp }}-q_{e, \mathrm{cal}}}{q_{e, \exp }}\right]^{2}}{(N-1)}}
$$

where $N$ is the number of data points, $q_{\mathrm{e}, \exp }$ and $q_{\mathrm{e}, \mathrm{cal}}$ $(\mathrm{mg} / \mathrm{g})$ are the experimental and calculated equilibrium adsorption capacity value, respectively [21]. The $\Delta q_{e}$ obtained for the pseudo-first-order kinetic model was



(a)



(b)

Figure 2. Adsorption kinetics of MB on the Fe-GAC. Conditions: Initial concentration of $\mathrm{MB}, 90,450$ and $1050 \mathrm{mg} / \mathrm{L}$; volume of solution, $60 \mathrm{~mL}$; initial solution $\mathrm{pH}, 6.0$; temperature, $20^{\circ} \mathrm{C}$; contact time, 300 - 500 min. (a) Pseudofirst-order kinetics; (b) Pseudo-second-order kinetics. 
Table 4. Kinetic parameters for MB adsorption onto Feamended GAC.

\begin{tabular}{|c|c|c|c|c|c|c|c|}
\hline \multirow{2}{*}{$\begin{array}{c}C_{0} \\
(\mathrm{mg} / \mathrm{L})\end{array}$} & \multirow{2}{*}{$\begin{array}{c}\text { Experimental } \\
q_{e}(\mathrm{mg} / \mathrm{g})\end{array}$} & \multicolumn{3}{|c|}{ Pseudo first order } & \multicolumn{3}{|c|}{ Pseudo second order } \\
\hline & & $\begin{array}{c}q_{e} \\
(\mathrm{mg} / \mathrm{g})\end{array}$ & $\begin{array}{c}k_{1} \\
\left(\min ^{-1}\right)\end{array}$ & $\mathrm{R}^{2}$ & $\begin{array}{c}q_{e} \\
(\mathrm{mg} / \mathrm{g})\end{array}$ & $\begin{array}{c}k_{2} \\
(\mathrm{~g} / \mathrm{mg} / \mathrm{min})\end{array}$ & $\mathrm{R}^{2}$ \\
\hline 90 & 10.3 & 12.8 & 0.028 & 0.9857 & 10.6 & 0.004 & 0.9984 \\
\hline 450 & 54.3 & 73.8 & 0.015 & 0.9737 & 57.7 & 0.0003 & 0.9824 \\
\hline 1050 & 125.7 & 167.6 & 0.013 & 0.9787 & 136.3 & 0.00011 & 0.9855 \\
\hline
\end{tabular}

$38.53 \%$, which is relatively high as compared to the $\Delta q_{e}$ values of $7.04 \%$ obtained for the pseudo-second order kinetic model. Base on the high correlation coefficient values and the low $\Delta q_{e}$ value, the pseudo second order model adequately described the experimental data of the adsorption of MB onto Fe-GAC. This suggested that the overall rate of the adsorption process was controlled by chemical sorption or chemisorption, which involved valency forces through sharing or exchange of electrons between the adsorbent and adsorbate [12]. The similar phenomena have been observed in the adsorption of MB on the bamboo-based activated carbon [22], the activated carbon prepared from rattan sawdust [23] and on the activated carbon from waste biomass by sulfuric acid activation [24].

\subsection{Heterogeneous Fenton Oxidation of the MB in the Fe-GAC}

Fenton and Fenton-like reaction for the treatment of wastewater are very efficient in a $\mathrm{pH}$ range between 2.8 and $3[25,26]$. In the present study, adjusting the $\mathrm{pH}$ of the MB-saturated Fe-GAC in the solution was not needed because the $\mathrm{pH}$ of solution after $\mathrm{MB}$ saturation onto Fe-GAC was approximately 3 . As the major reactions in Fenton oxidation describe in Equations (10)-(13), the excessive $\mathrm{H}_{2} \mathrm{O}_{2}$ and $\mathrm{Fe}^{2+}$ scavenge $\mathrm{OH}$ radical that is the major oxidant in Fenton oxidation used for non-specific oxidation of broad ranges of contaminants.

$$
\begin{aligned}
& \mathrm{Fe}^{2+}+\mathrm{H}_{2} \mathrm{O}_{2} \rightarrow \mathrm{Fe}^{3+}+\mathrm{OH}^{-}+\mathrm{HO} . \\
& \text { Contaminant }+\mathrm{HO} \cdot \rightarrow \mathrm{R} \cdot+\mathrm{H}_{2} \mathrm{O} \\
& \rightarrow \text { further oxidationto final products } \\
& \mathrm{HO} \cdot+\mathrm{H}_{2} \mathrm{O}_{2} \rightarrow \mathrm{HO}_{2} \cdot+\mathrm{H}_{2} \mathrm{O} \\
& \mathrm{HO} \cdot+\mathrm{Fe}^{2+} \rightarrow \mathrm{Fe}^{3+}+\mathrm{OH}^{-}
\end{aligned}
$$

Thus, the heterogeneous Fenton oxidation of $\mathrm{MB}$ in the Fe-GAC was carried out at various iron or $\mathrm{H}_{2} \mathrm{O}_{2}$ loading for figuring the optimum conditions for oxidation of MB in the Fe-GAC. To use a heterogeneous catalytic system in industrial practice it is important to evaluate the loss of catalyst from the support [26]. In this study, there was no leaching of iron in the solution after all oxidation process at $\mathrm{pH} 3$ and 20.

\subsubsection{Effect of Fe Loading on Oxidation of MB in the Fe-GAC}

In order to investigate the effect of the Fe loading on the $\mathrm{MB}$ oxidation in the Fe-GAC, the experiments were performed at the different $\mathrm{Fe}^{2+}$ loading of 0.5 to $15 \mathrm{mg} \mathrm{Fe} / \mathrm{g}$ GAC at the fixed concentration of $\mathrm{H}_{2} \mathrm{O}_{2}$ of $140 \mathrm{mmol}$ $\mathrm{H}_{2} \mathrm{O}_{2} / \mathrm{mmol} \mathrm{MB}$. Figure 3 shows the effect of $\mathrm{Fe}$ loading on oxidation of $\mathrm{MB}$ in the Fe-GAC to analyze the $1^{\text {st }}$ order rate constant and half-life of $\mathrm{H}_{2} \mathrm{O}_{2}$. It indicated enhancing the rate constant for $\mathrm{H}_{2} \mathrm{O}_{2}$ consumption while reducing the half-life of $\mathrm{H}_{2} \mathrm{O}_{2}$ at increasing iron loading in the GAC. Besides, the oxidation efficiency of $\mathrm{MB}$ in the Fe-GAC was close to $100 \%$ in all the conditions of Fe loading $(0.5 \mathrm{mg} / \mathrm{g} \mathrm{GAC}$ to $15 \mathrm{mg} / \mathrm{g} \mathrm{GAC})$ due to the excessive initial concentration of $\mathrm{H}_{2} \mathrm{O}_{2}$. Note that 36 moles of $\mathrm{H}_{2} \mathrm{O}_{2}$ are required to completely oxidize 1 mole of $\mathrm{MB}$ based on the balanced stoichiometric equation of oxidation of MB. Therefore, the effect of $\mathrm{H}_{2} \mathrm{O}_{2}$ concentration on the oxidation of MB in the Fe-GAC was investigated at the fixed loading of $\mathrm{Fe}(6 \mathrm{mg} \mathrm{Fe} / \mathrm{g} \mathrm{GAC})$.

\subsubsection{Effect of Single and Multiple $\mathrm{H}_{2} \mathrm{O}_{2}$ Injection on MB Oxidation}

Two sets of experiments with the single and the multiple application of the $\mathrm{H}_{2} \mathrm{O}_{2}$ to the MB-saturated Fe-GAC were designed to evaluate the effectiveness of the $\mathrm{H}_{2} \mathrm{O}_{2}$ application [27]. The initial hydrogen peroxide concentration was varied between 7 to $140 \mathrm{mmol} \mathrm{H}_{2} \mathrm{O}_{2} / \mathrm{mmol}$ $\mathrm{MB}$ with $6 \mathrm{mg} \mathrm{Fe} / \mathrm{g} \mathrm{GAC}$ from the previous section. The effect of the single application of $\mathrm{H}_{2} \mathrm{O}_{2}$ on $\mathrm{MB}$ oxidation is shown in Figure 4. The increase of the $\mathrm{H}_{2} \mathrm{O}_{2}$ concentration from 7 to $140 \mathrm{mmol} \mathrm{H}_{2} \mathrm{O}_{2} / \mathrm{mmol} \mathrm{MB}$ led to an increase in the MB removal efficiency from $62.6 \%$ to

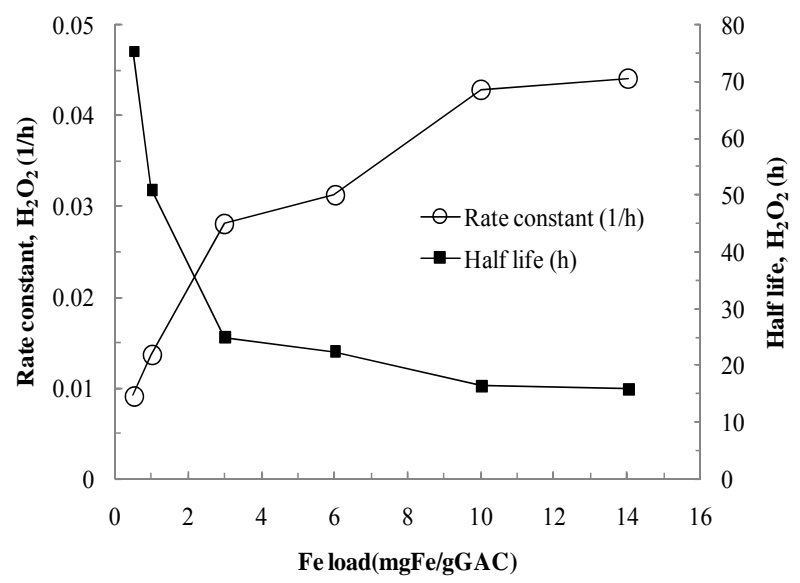

Figure 3. Effects of iron loading on oxidation of the MBspent Fe-GAC with the fixed $\mathrm{H}_{2} \mathrm{O}_{2}$ dose. Conditions: Initial concentration of $\mathrm{MB}, 1000 \mathrm{mg} / \mathrm{L}$; volume of solution, $60 \mathrm{~mL}$; initial solution $\mathrm{pH}, 6.0$; temperature, $20^{\circ} \mathrm{C}$. 


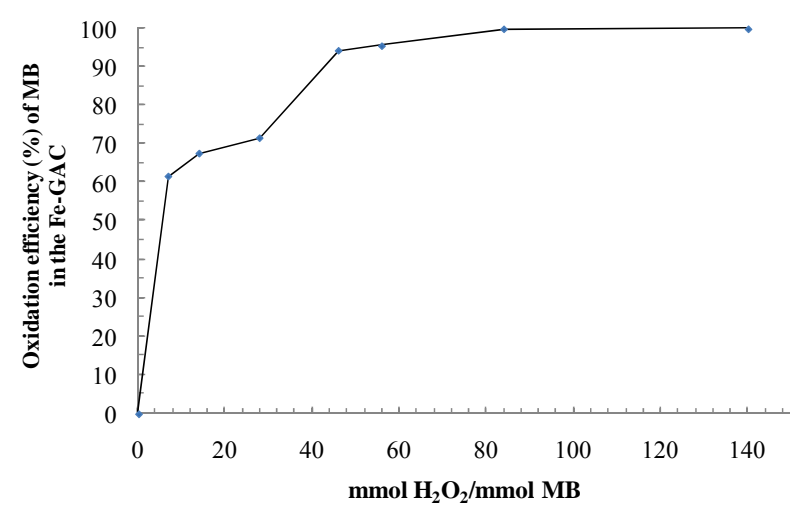

Figure 4. Effect of $\mathrm{H}_{2} \mathrm{O}_{2}$ on the oxidation of $\mathrm{MB}$ in the Fe-GAC. Conditions: Initial concentration of $\mathrm{MB}, 1000$ $\mathrm{mg} / \mathrm{L}$; volume of solution, $60 \mathrm{~mL}$; initial solution $\mathrm{pH}, 6.0$; temperature, $20^{\circ} \mathrm{C}$.

$100 \%$, respectively. The selection of this optimum concentration is important from the commercial point of view due to the high cost of $\mathrm{H}_{2} \mathrm{O}_{2}$ [28].

For the multiple $\mathrm{H}_{2} \mathrm{O}_{2}$ application, one fourth of $\mathrm{H}_{2} \mathrm{O}_{2}$ amount was added at four different points of time. The initial $\mathrm{H}_{2} \mathrm{O}_{2}$ loadingof $28 \mathrm{mmol}_{2} \mathrm{O}_{2} / \mathrm{mmol} \mathrm{MB}$ was selected from the previous experiment with $6 \mathrm{mg} \mathrm{Fe} / \mathrm{g}$ GAC. It was lower than the stoichiometric demand of $\mathrm{H}_{2} \mathrm{O}_{2}$ for the complete mineralization of MB (36 mmol of $\mathrm{H}_{2} \mathrm{O}_{2}$ per mmol of $\mathrm{MB}$ ). The results showed that the $\mathrm{MB}$ oxidation efficiency of multiple $\mathrm{H}_{2} \mathrm{O}_{2}$ application was $84.1 \%$, which was higher than that by a single $\mathrm{H}_{2} \mathrm{O}_{2}$ application which was $71.6 \%$. The multiple additions of $\mathrm{H}_{2} \mathrm{O}_{2}$ are more effective than the single addition of $\mathrm{H}_{2} \mathrm{O}_{2}$ because scavenging of $\mathrm{OH}$ radicals due to the excessive $\mathrm{H}_{2} \mathrm{O}_{2}$ could be reduced with the staged application of $\mathrm{H}_{2} \mathrm{O}_{2}$ [27].

\section{Conclusion}

The present study presents that the acid-treated iron amended activated carbon (Fe-GAC) is an effective adsorbent and catalyst for the adsorption and oxidation of methylene blue from aqueous solution. The modification of carbon surface by acid treatment has proven to play an important role for more uniform deposition of iron in the GAC. The equilibrium data were fitted to linear models of Freundlich and Langmuir model, and the equilibrium data of Fe-GAC were best described by the Langmuir isotherm model with the maximum monolayer adsorption capacity of $238.1 \mathrm{~m} \pm 0.78 \mathrm{mg} / \mathrm{g}$ at $20^{\circ} \mathrm{C}$. Adsorption kinetic studies of MB demonstrated that the adsorption rate followed the pseudo-second-order kinetic model. For the heterogeneous Fenton oxidation of $\mathrm{MB}$ in the $\mathrm{Fe}$ GAC, the increase of $\mathrm{H}_{2} \mathrm{O}_{2}$ concentration from 7 to 140 mmol $\mathrm{H}_{2} \mathrm{O}_{2} / \mathrm{mmol} \mathrm{MB}$ led to an increase in $\mathrm{MB}$ removal efficiency from $62.6 \%$ to $100 \%$. Besides, the multiple application of $\mathrm{H}_{2} \mathrm{O}_{2}$ to the MB-saturated Fe-GAC in- creased the oxidation efficiency of MB in the GAC up to $84.1 \%$ which was more effective than that by the single application of $\mathrm{H}_{2} \mathrm{O}_{2}$.

\section{REFERENCES}

[1] S. Khorramfar, N. M. Mahmoodi, M. Arami and K. Gharanjig, "Equilibrium and Kinetic Studies of the Cationic Dye Removal Capability of a Novel Biosorbent Tamarindus Indica from Textile Wastewater," Coloration Technology, Vol. 126, No. 5, 2010, pp. 261-268. doi:10.1111/j.1478-4408.2010.00256.x

[2] S. Khorramfar, N. M. Mahmoodi, M. Arami and H. Bahrami, "Oxidation of Dyes from Colored Wastewater Using Activated Carbon/Hydrogen Peroxide," Desalination, Vol. 279, No. 1-3, 2011, pp. 183-189.

doi:10.1016/j.desal.2011.06.005

[3] H. J. Fan, H. Y. Shu and K. Tajima, "Decolorization of Acid Black 24 by the FeGAC/ $\mathrm{H}_{2} \mathrm{O}_{2}$ Process," Journal of Hazardous Materials, Vol. 128, No. 2-3, 2006, pp. 192200. doi:10.1016/j.jhazmat.2005.07.059

[4] V. P. Santos, M. F. R. Pereira, P. C. C. Faria and J. J. M. Orfao, "Decolourisation of Dye Solutions by Oxidation with $\mathrm{H}_{2} \mathrm{O}_{2}$ in the Presence of Modified Activated Carbons," Journal of Hazardous Materials, Vol. 162, No. 2-3, 2009, pp. 736-742. doi:10.1016/j.jhazmat.2008.05.090

[5] S. G. Huling, P. K. Jones, W. P. Ela and R. G. Arnold, "Fenton-Driven Chemical Regeneration of MTBE-Spent GAC," Water research, Vol. 39, No. 10, 2005, pp. 2145 2153. doi:10.1016/j.watres.2005.03.027

[6] S. G. Huling, P. K. Jones and T. R. Lee, "Iron Optimization for Fenton-Driven Oxidation of MTBE-Spent Granular Activated Carbon," Environmental Science and Technology, Vol. 41, No. 11, 2007, pp. 4090-4096. doi:10.1021/es062666k

[7] E. Kan and S. G. Huling, "Effects of Temperature and Acidic Pre-Treatment on Fenton-Driven Oxidation of MTBESpent Granular Activated Carbon," Environmental Science and Technology, Vol. 43, No. 5, 2009, pp. 14931499. doi:10.1021/es802360f

[8] S. G. Huling, E. Kan and C. Wingo, "Fenton-Driven Regeneration of MTBE-Spent Granular Activated CarbonEffects of Particle Size and Iron Amendment Procedures,' Applied Catalysis B-Environmental, Vol. 89, No. 3-4, 2009, pp. 651-658. doi:10.1016/j.apcatb.2009.02.002

[9] I. Langmuir, "The Adsorption of Gases on Plane Surfaces of Glass, Mica and Platinum," Journal of American Chemical Society, Vol. 40, No. 9, 1918, pp. 1361-1403. doi:10.1021/ja02242a004

[10] H. Freundlich, "Over the Adsorption in Solution," Journal of Physical Chemistry, Vol. 57, 1906, pp. 385-470.

[11] S. Lagergren, "About the Theory of So-Called Adsorption of Soluble Substances," Kungliga Svenska Vetenskapsakademiens Handlingar, Vol. 24, No. 4, 1898, pp. 1-39.

[12] Y. S. Ho and G. McKay, "Pseudo-Second Order Model for Sorption Processes," Process Biochemistry, Vol. 34, No. 5, 1999, pp. 451-465. doi:10.1016/S0032-9592(98)00112-5 
[13] T. A. Kurniawan and W. H. Lo, "Removal of Refractory Compounds from Stabilized Landfill Leachate Using an Integrated $\mathrm{H}_{2} \mathrm{O}_{2}$ Oxidation and Granular Activated Carbon (GAC) Adsorption Treatment," Water Research, Vol. 43, No. 16, 2009, pp. 4079-4091. doi:10.1016/j.watres.2009.06.060

[14] F. Raposo, M. A. De La Rubia and R. Borja, "Methylene Blue Number as Useful Indicator to Evaluate the Adsorptive Capacity of Granular Activated Carbon in Batch Mode: Influence of Adsorbate/Adsorbent Mass Ratio and Particle Size," Journal of Hazardous Materials, Vol. 165, No. 1-3, 2009, pp. 291-299. doi:10.1016/i.jhazmat.2008.09.106

[15] G. G. Stavropoulos and A. A. Zabaniotou, "Production and Characterization of Activated Carbons from OliveSeed Waste Residue," Microporous and Mesoporous Materials, Vol. 82, No. 1-2, 2005, pp. 79-85. doi:10.1016/j.micromeso.2005.03.009

[16] W. J. Weber, "Physiochemical Properties for Water Quality Control,” John Wiley and Sons Inc, New York, 1972.

[17] E. N. El Qada, S. J. Allen and G. M. Walker, "Adsorption of Basic Dyes from Aqueous Solution onto Activated Carbons," Chemical Engineering Journal, Vol. 135, No. 3, 2008, pp. 174-184. doi:10.1016/j.cej.2007.02.023

[18] S. B. Wang, Z. H. Zhu, A. Coomes, F. Haghseresht and G. Q. Lu, "The Physical and Surface Chemical Characteristics of Activated Carbons and the Adsorption of Methylene Blue from Wastewater," Journal of Colloid and Interface Science, Vol. 284, No. 2, 2005, pp. 440-446. doi:10.1016/j.jcis.2004.10.050

[19] C. Lai and C. Y. Chen, "Removal of Metal Ions and Humic Acid from Water by Iron-Coated Filter Media," Chemosphere, Vol. 44, No. 5, 2001, pp. 1177-1184. doi:10.1016/S0045-6535(00)00307-6

[20] C. Moreno-Castilla, "Adsorption of Organic Molecules from Aqueous Solutions on Carbon Materials," Carbon, Vol. 42, No. 1, 2004, pp. 83-94. doi:10.1016/j.carbon.2003.09.022

[21] B. H. Hameed, I. A. W. Tan and A. L. Ahmad, "Adsorption Isotherm, Kinetic Modeling and Mechanism of 2,4,6-
Trichlorophenol on Coconut Husk-Based Activated Carbon," Chemical Engineering Journal, Vol. 144, No. 2, 2008, pp. 235-244. doi:10.1016/j.cej.2008.01.028

[22] B. H. Hameed, A. M. Din and A. Ahmad, "Adsorption of Methylene Blue onto Bamboo-Based Activated Carbon: Kinetics and Equilibrium Studies," Journal of Hazardous Materials, Vol. 141, No. 3, 2007, pp. 819-825. doi:10.1016/j.jhazmat.2006.07.049

[23] B. H. Hameed, A. Ahmad and K. Latiff, "Adsorption of Basic Dye (Methylene Blue) onto Activated Carbon Prepared from Rattan Sawdust," Dyes and Pigments, Vol. 75, No. 1, 2007, pp. 43-49. doi:10.1016/j.dyepig.2006.05.039

[24] S. Karagöz, T. Tay, S. Ucar and M. Erdem, "Activated Carbons from Waste Biomass by Sulfuric Acid Activation and Their Use on Methylene Blue Adsorption," Bioresource Technology, Vol. 99, No. 14, 2008, pp. 62146222. doi:10.1016/j.biortech.2007.12.019

[25] M. Pérez, F. Torrades, J. A. García-Hortal, X. Domènech and J. Peral, "Removal of Organic Contaminants in Paper Pulp Treatment Effluents under Fenton and Photo-Fenton Conditions," Applied Catalysis B: Environmental, Vol. 36, No. 1, 2002, pp. 63-74 doi:10.1016/S0926-3373(01)00281-8

[26] J. H. Ramirez, C. A. Costa, L. M. Madeira, G. Mata, M. A. Vicente, M. Rojas-Cervantes, et al., "Fenton-Like Oxidation of Orange II Solutions Using Heterogeneous Catalysts Based on Saponite Clay," Applied Catalysis B: Environmental, Vol. 71, No. 1-2, 2007, pp. 44-56. doi:10.1016/j.apcatb.2006.08.012

[27] D. Kim, J. K. C. Chen and T. F. Yen, "Naval Derusting Wastewater Containing High Concentration of Iron, Treated in UV Photo-Fenton-Like Oxidation," Journal of Environmental Sciences, Vol. 22, No. 7, 2010, pp. 991-997. doi:10.1016/S1001-0742(09)60209-6

[28] K. Dutta, S. Mukhopadhyay, S. Bhattacharjee and B. Chaudhuri, "Chemical Oxidation of Methylene Blue Using a Fenton-Like Reaction," Journal of Hazardous Materials, Vol. 84, No. 1, 2001, pp. 57-71. doi:10.1016/S0304-3894(01)00202-3 